\title{
BREVE HISTORIA DE LA HISTORIA CONSIDERADA COMO PRODUCTO DISCURSIVO ${ }^{1}$
}

Por:

Manuel Silva Rodríguez

Profesor asociado

Escuela de Comunicación Social

Universidad del Valle

manuel.silva@correounivalle.edu.co

\section{Resumen:}

Este artículo expone algunos modos como ha sido considerada la historia en su doble concepción: en cuanto ciencia y en cuanto hechos del pasado. El texto pone el énfasis en la manera en que la historia ha llegado a ser considerada como un tipo de escritura que obedece a un pacto y a unos propósitos particulares que logran diferenciarla de la producción discursiva ficcional.

Palabras claves: imaginación, historia, interpretación, pasado, presente, relato, veracidad.

\begin{abstract}
:
This article expounds some ways in which the history has been considered: as a science and as past events. The text emphasizes in the way that history has came to be regarded as a type of writing that obeys to a pact and some particulars purposes that differentiate it from fictional production discourse.
\end{abstract}

Key Words: imagination, history, interpretation, past, present, tale, veracity. 


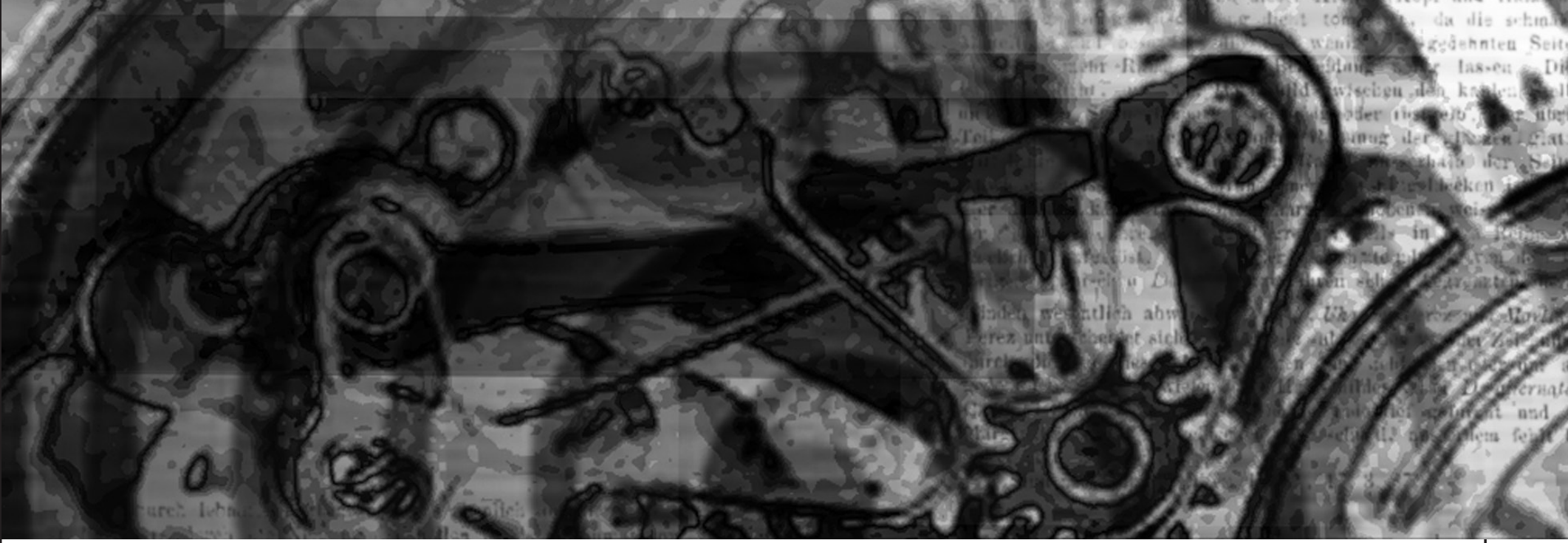

\section{Sentidos del término «historia»}

Con el ánimo de precisar el contenido del término «historia», es pertinente empezar recordando la variedad de significados que alberga esta palabra. Siguiendo, sobre todo, las precisiones conceptuales introducidas por Hegel, historiadores y filósofos de la historia han advertido que la ambigüedad del vocablo puede conducir a la confusión de instancias distintas. Es sabido que el término «historia» designa el objeto o la materia de la disciplina - la llamada historiam rerum gestarum, los acontecimientos o situaciones del pasado - y a la vez la indagación acerca de tal objeto - la res gestas, la práctica intelectual propiamente dicha-, cuyo resultado consiste, principal aunque no exclusivamente, en un discurso escrito, en lo que se denomina también como historiografía.

El historiador y pensador del estatuto epistemológico de la historia Michel de Certeau, por ejemplo, desagrega los contenidos del término diciendo que "entiendo por historia esta práctica (una «disciplina»), su resultado (el discurso), o su relación bajo la forma de una «producción». Ciertamente, en el uso ordinario el término historia connota a la vez a la ciencia y a su objeto - la explicación que se dice y la realidad que ya pasó o está pasando" (1978: 35$)^{2}$.

Además, y este es un factor que ha sumando otra dosis de confusión en el dominio de la investigación y la escritura de la historia, con el término «historia» se han designado simultáneamente el relato histórico o de hechos históricos y el relato de hechos imaginados. Es decir, la misma palabra ha servido para denominar dos tipos de relato - el histórico y el de ficción — sustancialmente distintos. Dos tipos de relato que desde el punto de vista de los objetivos del productor del discurso y de las expectativas de sus receptores — en general, desde la perspectiva de la pragmática de la comunicación literaria-, poseen estatutos distintos y en principio apuntan hacia fines diferentes. 


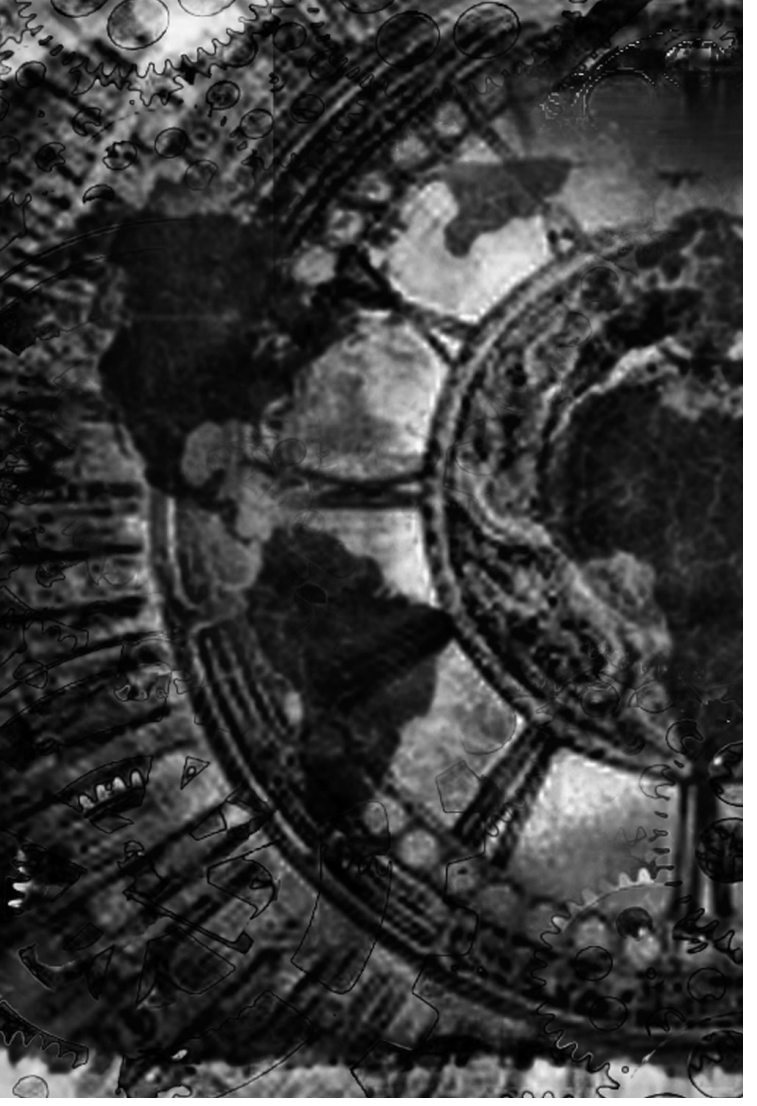

El uso de la palabra «historia» para nombrar dos producciones del lenguaje distintas, aunque también próximas, tiene origen en la utilización común de la narración como un mecanismo de ordenación y comprensión de la experiencia y de la configuración del discurso ${ }^{3}$. Este hecho es advertido, por ejemplo, por el historiador Jacques Le Goff, quien aclara que además de referirse a una disciplina intelectual y a su objeto de estudio el vocablo "historia puede tener un tercer significado, precisamente el de «relato». Una historia es un relato que puede ser verdadero o falso, con una base de «realidad histórica», o meramente imaginario, y éste puede ser un relato «histórico»o bien una fábula” (1977: 22) .

\section{La historia como testificación del pasado}

La historia entendida como el decir sobre sucesos del pasado comenzó en la Antigüedad, por lo menos en Occidente, con Herodoto, Tucídides y Jenofonte. Estudiosos de la historia como Carlos Rama (1981), Jorge Lozano (1987) y Jacques Le Goff (1977) coinciden en señalar esa circunstancia y en destacar el carácter de investigación y testificación que entonces poseía la escritura en relación con unos acontecimientos determinados. Este carácter obedecía, precisamente, a un principio de respeto por la verdad e implicaba que, para ser fiable, el escritor hubiese tenido una experiencia directa del asunto sobre el cual se proponía tratar, condición que decidía una actitud prácticamente testimonial del autor.

De ahí que el criterio de autoridad del historiador fuera su visión inmediata de los acontecimientos, con lo cual eran asimilados percepción y conocimiento ${ }^{5}$. Tener la visión como principio de fiabilidad, además, presuponía el concepto de que el relato de lo visto era verdadero porque presentaba la imagen fiel de lo acontecido: "El yo he visto se sitúa, entonces, como garante de verdad y como autor fiable tanto de los hechos que cuenta como del decir mismo; no es cualquiera el que habla, sino alguien que fue testigo" (Lozano, 1987: 19). Tal condición, pues, suponía la asunción de la escritura como reflejo de los acontecimientos, como mímesis en un sentido platónico.

La preferencia por la percepción visual, además, relegaba a un segundo plano las fuentes orales. Este recurso, que podía sustituir la carencia de la visión directa de los acontecimientos por testimonios de testigos, ocupaba una escala de valor inferior en relación con la experiencia inmediata del escritor ${ }^{6}$. 
Como lo recuerda Jorge Lozano (1987: 25-28), la concepción de la historia como testimonio acerca de acontecimientos sobre los que se había tenido experiencia directa, en la antigüedad también acarreaba la consecuencia de que el pasado lejano no fuera considerado materia de interés para los historiadores. Por ello, la historia contenida en los primeros textos historiográficos es prácticamente historia contemporánea.

La Edad Media heredó de la Antigüedad el sentido de la historia como testimonio. Sin embargo, la adopción de tal principio tuvo como consecuencia la convicción de que el pasado sólo se podía conocer por la fe depositada en quienes habían tenido una experiencia de él ${ }^{7}$. Es decir, la confianza y la fe fueron depositadas en quienes poseían la autoridad, en quienes eran dignos de crédito: "los historiadores medievales tuvieron que basarse en los relatos proporcionados por la tradición y cuya autoridad fuera reconocida: la Iglesia, tal o cual monarquía, una universidad, la alta posición o la santidad del que la transmite" (Lozano, 1987: 31).

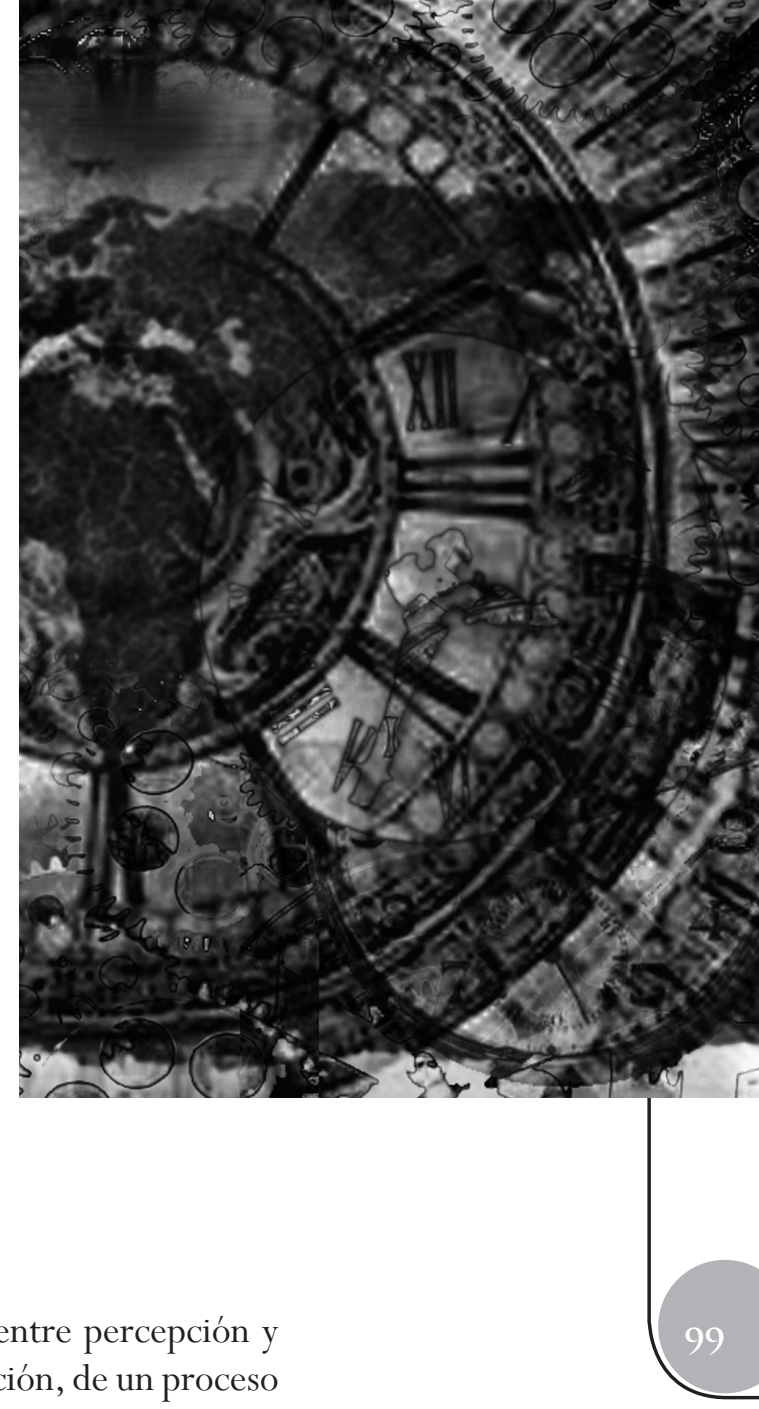
intelectual- abrió el camino hacia una mentalidad que concibiera como posible acceder a un conocimiento del pasado sin tener como condición que quien produzca ese saber haya vivido lo acontecido, o que la fe en su palabra sea su único garante. Es durante tal transformación cultural cuando la antigua concepción de la historia da lugar a un concepto de historia como proceso de lectura de fuentes históricas. La idea de historia propia de la Antigüedad definida por la percepción directa o en su defecto el relato de un tercero que había sido testigo de lo sucedido, el interés por lo visible en detrimento de lo invisible, así como la fe en los relatos de autoridades medievales, con los cambios iniciados en el Renacimiento cedieron su lugar a la posibilidad de descifrar el pasado a partir de unas fuentes ${ }^{8}$.

Este momento es de gran significación en la configuración del concepto de historia como disciplina moderna, porque entonces comienza el desarrollo de técnicas y métodos de indagación e interpretación de documentos. Así, dice Jorge Lozano, la historia "se transforma en un discurso justificado a su vez en la validez de técnicas y métodos, aplicados a los monumentos y documentos, que consientan la aprehensión del pasado" (1987: 40) ${ }^{9}$. Tras los cambios que la concepción de la historia experimentó en el periodo comprendido aproximadamente entre el final de la Edad Media y la Revolución Francesa, en el siglo XIX la historia adquirió independencia con respecto de otras disciplinas y fue elevada a la categoría de ciencia: "en este siglo se definió la Historia como un conocimiento científico y, perfeccionando sus métodos técnicos, se independizó de la literatura y creció como disciplina científica” (Rama, 1981: 45). 
Ahora bien, en tanto que producción intelectual, la historia heredó de la Antigüedad el espíritu de la verdad. Por esta razón, en el orden epistemológico la historia obedece a un criterio de verdad que descansa sobre el respeto, la fidelidad y la posibilidad de comprobar lo dicho acerca del pasado en relación con unas fuentes de donde procede la información. Así, por ejemplo, antes de adentrarse en el estudio detallado del discurso histórico, Paul Ricoeur deja claro que en "cierto nivel del análisis y de la argumentación, el concepto convencional de «verdad», definido en términos de verificación y de falsación empíricas, es perfectamente válido (...) la verificación o la falsación históricas tampoco ponen en juego un concepto de «verdad» diferente al que adopta la física” (1999: 35). Este rasgo de la escritura de la historia fue advertido por Aristóteles, aunque obviamente en otros términos, cuando en su famoso pasaje de la Poética señaló que la historia dice — en nuestro tiempo diremos que pretende decir o hablar de - las cosas como fueron y la poesía como podrían ser:

Pues el historiador y el poeta no difieren en que uno utilice la prosa y el otro el verso (se podría trasladar al verso la historia de Heródoto, y no sería menos historia en verso que sin verso), sino que la diferencia reside en que el uno dice lo que ha acontecido, el otro lo que podría acontecer. Por esto la poesía es más filosófica y mejor que la historia, pues la poesía dice más lo universal, mientras que la historia es sobre lo particular (Aristóteles, 2000: 1451b) ${ }^{10}$.

En el siglo XIX, tal sentido de lo verdadero se mantuvo en el afianzamiento de la disciplina gracias al método - luego objeto de críticas - impulsado por el historiador alemán T. von Ranke. En efecto, convencido de que para decir la verdad el historiador podía excluir todo asomo de subjetividad en su indagación y reconstrucción del pasado, "abandonar sus intereses y sus pasiones a fin de poder ver la realidad histórica tal como era” (Lozano, 1987: 81), Ranke abogó por una objetividad a prueba de toda interferencia basado en su consigna metodológica de sujetarse a los documentos y presentar el pasado tal y como sucedió ${ }^{11}$. Ranke apoyaba su confianza en lograr la objetividad en la convicción de que los hechos del pasado podían ser fijados en las fuentes históricas y luego reflejados en un discurso «objetivo». Como se sabe, Ranke entendía la narración como una forma objetiva, por lo cual recurría al relato en tercera persona convencido de que la omnisciencia narrativa podía presentar los hechos como si hablaran por sí mismos, ajenos a la subjetividad del historiador.

En el afianzamiento de la disciplina en el siglo XIX, además, tuvo que ver la «demanda» de historia, un deseo creciente de conocer el pasado y de aprovechar este conocimiento para fortalecer las identidades nacionales de unos pueblos sacudidos por los efectos de la Revolución Francesa y el Romanticismo. Carlos Rama subraya que el nuevo estatuto adquirido por la historia en el siglo XIX y su afianzamiento "no habrían sido posibles, o por lo menos se habrían cumplido en un plazo mayor, si no hubiera existido el aliciente de un masivo interés de los lectores del siglo por la Historia” (1981: 46).

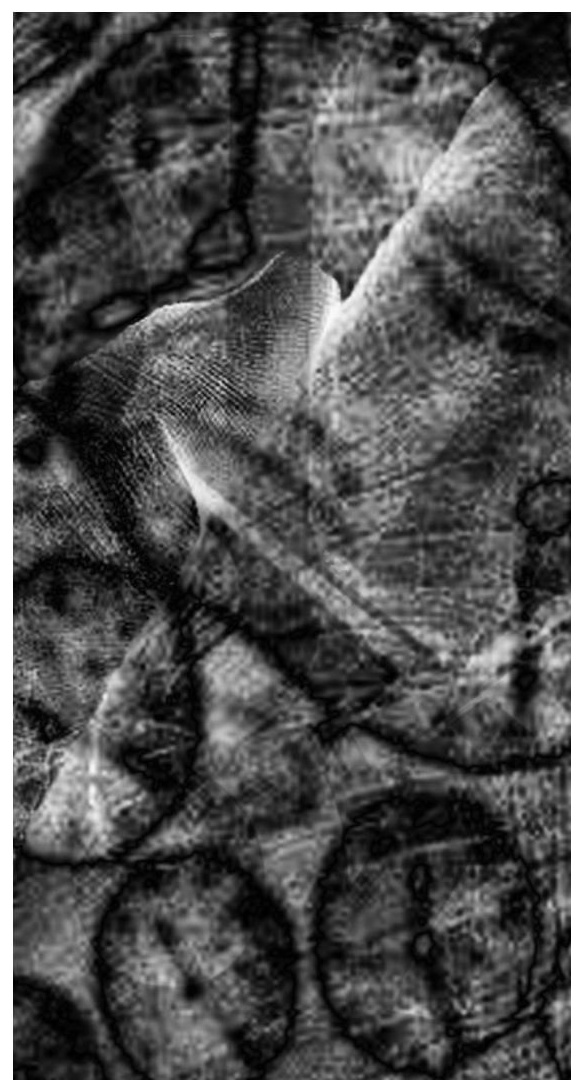


Este historiador recuerda que es entonces cuando la historia se convierte en cátedra universitaria, pues “dejando de ser exclusivo acervo de los príncipes o los poderosos, la Historia ingresa en los estudios organizados en forma regular”. Y, agrega también, la "idea, surgida de la Revolución Francesa, que hacía de la Historia un instrumento para forjar una nacionalidad, adquiere singular importancia en los nuevos Estados Nacionales".

Tratándose de una ciencia que recién se constituía, la confianza acaudillada por Ranke en que los documentos eran en sí mismos el pasado, los hechos, condujo a que pronto se aplicaran en la historia las metodologías propias de las ciencias naturales. Lo importante, entonces, era que el método permitiera fijar leyes para relacionar los hechos, los cuales estaban dados en los archivos. De esta manera el positivismo hizo tránsito hacia la historia, pues los historiadores creyeron encontrar en los métodos positivistas la solidez científica de la que su novel disciplina parecía carecer con respecto a las ciencias de la naturaleza.

E. H. Carr recuerda que los "positivistas, ansiosos por consolidar su defensa de la historia como ciencia, contribuyeron con el peso de su influjo a este culto de los hechos. Primero averiguad los hechos, decían los positivistas; luego deducid de ellos las conclusiones" (1961:12). Para los positivistas, añade, la historia "consiste en un cuerpo de hechos verificados. Los hechos los encuentra el historiador en los documentos, en las inscripciones, etcétera, lo mismo que los pescados sobre el mostrador de una pescadería”.

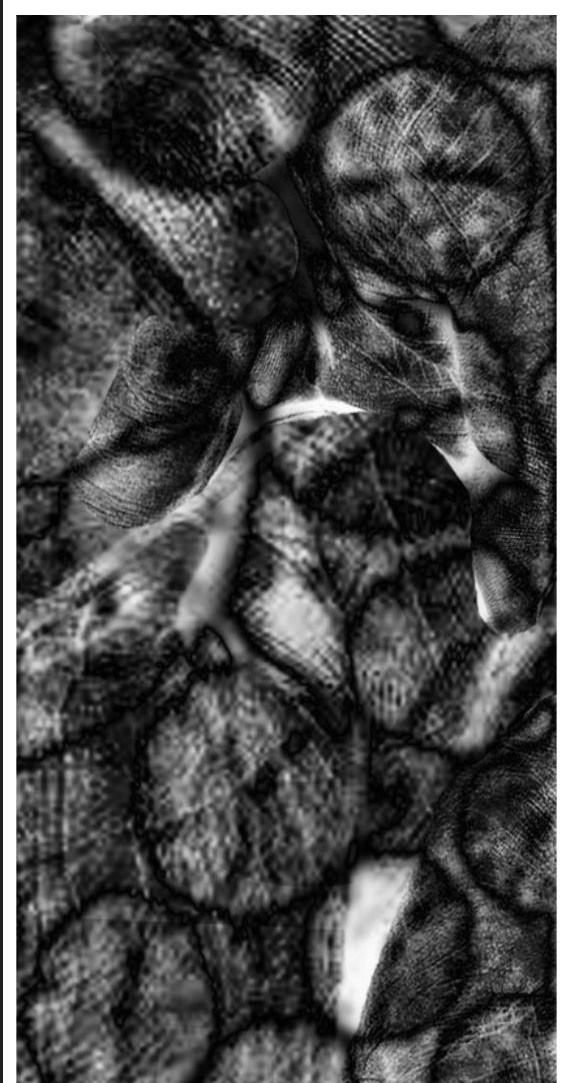

\section{La historia como interpretación}

La crítica de Nietzsche de 1874 en De la utilidad y los inconvenientes de la historia para la vida, se dirigió contra el positivismo y la concepción de la historia como reflejo objetivo del pasado asociado sólo con los grandes hombres y los grandes sucesos. En ese opúsculo, con su efectismo verbal característico Nietzsche censuró como "una fiebre histórica devorante" el historicismo reinante en aquellos años ${ }^{12}$. Nietzsche llegó a concluir que entre la vida y la historia se había interpuesto un obstáculo, "un astro brillante y magnífico, y la constelación ha quedado realmente alterada - a causa de la ciencia, por la pretensión de hacer de la historia una ciencia". Por el mismo motivo, Nietzsche cuestionó de la relación que entonces se mantenía con el pasado la sobrevaloración de la objetividad y, en consecuencia, el desconocimiento de la subjetividad: “¿No se introduce ya una cierta ilusión incluso en la interpretación más elevada del término «objetividad»? Suele entenderse generalmente esta palabra como un estado en el que el historiador contempla un acontecimiento en todos sus motivos y consecuencias con una pureza tal que no ha de ejercer ningún efecto sobre su subjetividad" (Nietszche, 1874: 99). 


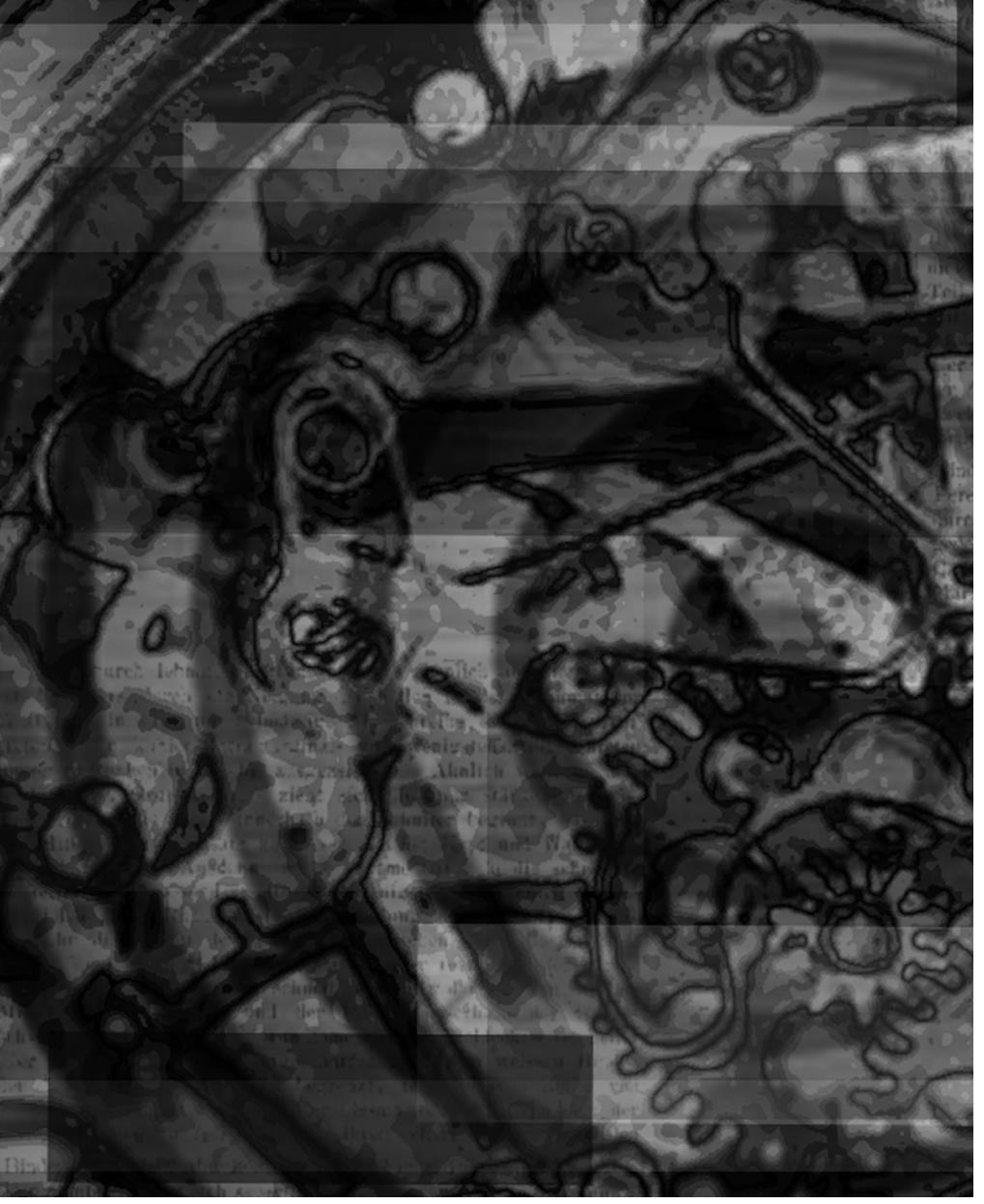

Una reacción similar se registró en el dominio de la historiografía, cuando los historiadores dirigieron su crítica contra la extensión a la historia de la confianza absoluta en la ciencia positiva ${ }^{13}$. El criterio de objetividad en la investigación defendido por Ranke fue criticado y, cabe decir, sustituido por la conciencia de que la historia es sobre todo una disciplina basada en la interpretación. Un ejemplo de los historiadores que con más claridad adoptaron esta posición es E. H. Carr: "Ante todo, los hechos de la historia nunca nos llegan en estado «puro», ya que ni existen ni pueden existir en forma pura: siempre hay una refracción al pasar por la mente de quien los recoge" (1961: 30). Este historiador insistió en que prácticamente un acontecimiento pasa a ser considerado como un hecho histórico mediante un acuerdo, cuando es aceptado como tal por los historiadores. Es decir, cuando existe cierto consenso alrededor de la valoración del presunto hecho: "Su condición de hecho histórico dependerá de una cuestión de interpretación. Este elemento interpretativo interviene en todos los hechos históricos" (1961: 17).

Tal carácter del hecho histórico puso de relieve, como mínimo, dos circunstancias que dieron lugar a algunos de los análisis más interesantes vinculados con la historia. Por una parte, en la historia fue reconsiderado el papel de la subjetividad del historiador. Contra el casi desprestigio con que cargaba la subjetividad en una concepción de la historia como la representada por Ranke, se repensó la objetividad en términos de rigor epistemológico y se reconoció la presencia inevitable del factor subjetivo diferenciado de la simple arbitrariedad ${ }^{14}$.

Por otra parte $-\mathrm{y}$ ésta es quizás la cualidad más significativa cuando se ponen frente a frente, por ejemplo, la historia y la novela, como una producción discursiva que también nos habla del pasado-- se reconoció que un acontecimiento adquiere la categoría de hecho histórico como fruto de la interpretación, de las relaciones que establece dentro de un sistema conformado por varios acontecimientos. Así, E. H. Carr afirmó que en "general puede decirse que el historiador encontrará la clase de hechos que busca. Historiar significa interpretar” (1961: 32). En sentido similar se manifestó el historiador Lucien Febvre, quien, según Le Goff, dijo: "No dado, sino creado por el historiador — ¿y cuántas veces? Inventado y creado mediante hipótesis y conjeturas, a través de un trabajo delicado y apasionante (...) Elaborar un hecho significa construirlo". Por ello, añade el propio Le Goff: "No hay hecho o hecho histórico sino dentro de una historia-problema” (1977: 34). 
La aceptación de que el hecho histórico se construye significa, por lo tanto, que la historia no es mímesis —imagen reflejo — del pasado, sino una construcción. Y construcción quiere decir que es una producción discursiva ${ }^{15}$. Como indagación, la historia concluye en un discurso - ya sea escrito o producido en otro tipo de leguaje - cuyo objeto es proporcionar conocimiento sobre el pasado, y esto resalta de antemano la cualidad de la historia como realización discursiva. La idea de la Antigüedad de que la historia daba cuenta fidedigna de lo visto por el historiador, reformulada en el siglo XIX por la confianza de los historiadores positivistas en que los documentos permitían recuperar objetivamente el pasado, al ser criticada arrojó como resultado la aclaración de que la historia es un decir sobre lo que alguna vez sucedió. Un decir, claro está, basado en unas fuentes y en el rigor metodológico.

Ahora bien, ello no excluye, desde luego, que también pueda existir una historia oral $^{16}$. Pero, sobre todo, la historia que se construye, que se transmite y que se critica es la historia fijada en la escritura, al punto que, no pocas veces, la historia oral es apenas valorada como testimonio, es decir tomada como fuente, para la historia escrita: "La historia es, sobre todo, historiografía, escritura, forma de representación de un modelo de realidad, el modelo de la realidad histórica" (Fernández, 1998:40). Por este motivo — su apreciación fundamentalmente como escritura-, la historia establece desde la antigüedad unas relaciones singulares, complejas en algunos casos, con otras producciones discursivas, especialmente con aquello que desde la perspectiva moderna se considera «literatura».

Además, como producción, la historia está cada vez condicionada por diversos factores - por ejemplo ideológicos - y basada en una selección de asuntos o problemas realizada en función de unas preguntas, de unos intereses. La historia, en consecuencia, no es todo el pasado sino una parte de él, de ahí que lo que se pueda entender como historia en un momento y sobre un periodo determinados pueda diferir de lo que se considere como histórico en otro momento, pues tal consideración se formulará de acuerdo con los criterios que en cada caso rijan la selección de los hechos. Fernández Prieto concluye con bastante claridad esta peculiaridad de la historia, cuando afirma que "no todo lo real es histórico. Ambos atributos no deben ser confundidos ni asimilados, aunque tradicionalmente sus relaciones hayan sido y sigan siendo muy estrechas" (1998: 40).

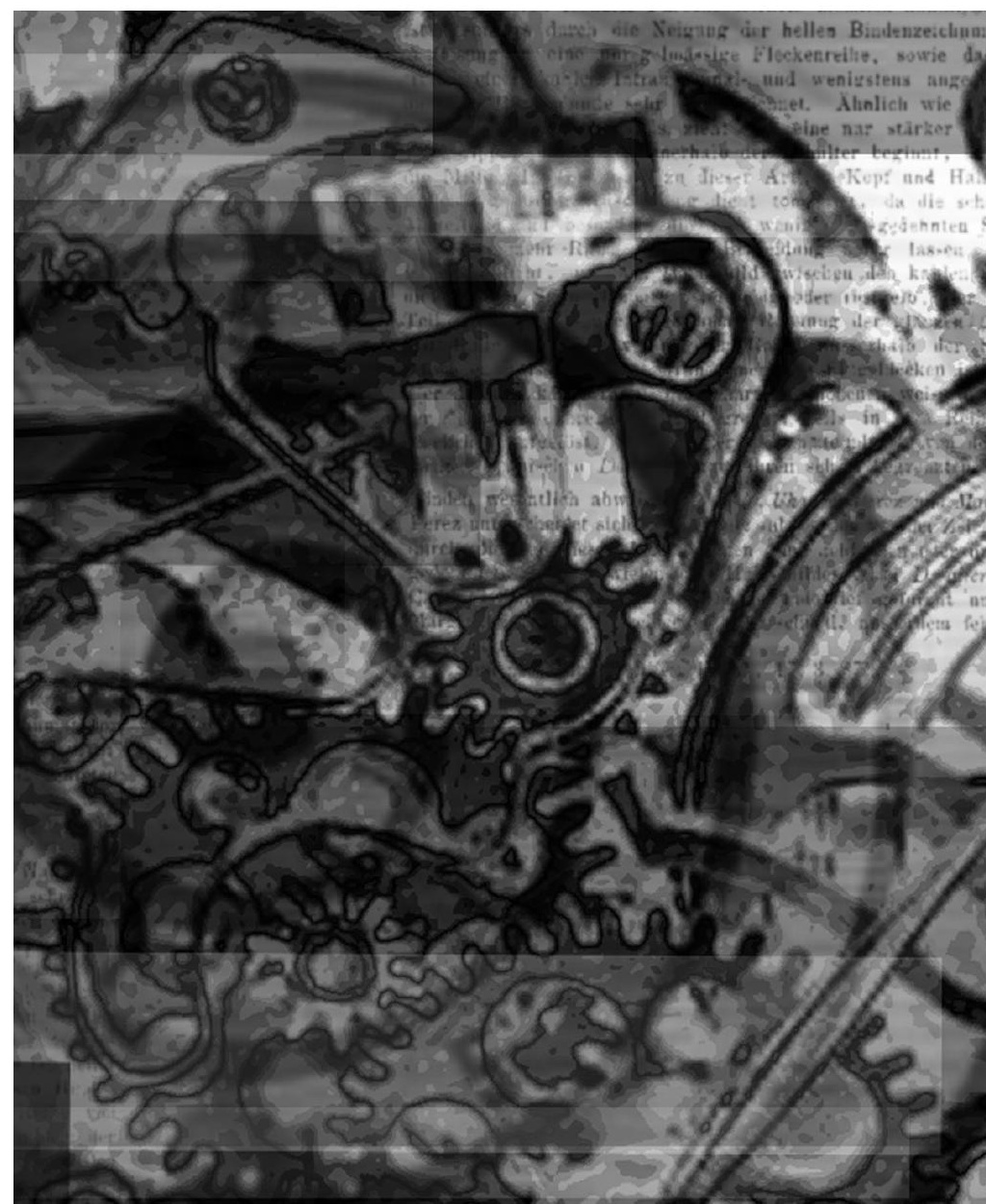




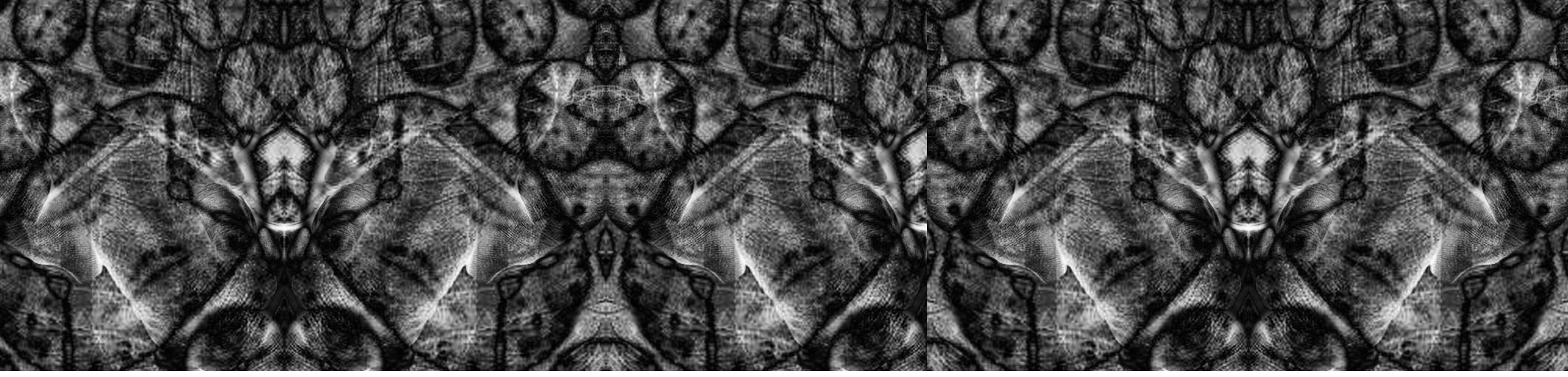

\section{A modo de conclusión}

Entendida como interpretación, la historia permite pensar que el pasado se ilumina desde el presente, cada presente puede mirar con ojos distintos el pasado. Para E. H. Carr, quien hemos visto que fue de los más claros en defender tal posición, la cuestión de la historia se define así: "Mi primera contestación a la pregunta de qué es la Historia, será pues la siguiente: un proceso continuo de interacción entre el historiador y sus hechos, un diálogo sin fin entre el presente y el pasado" $(1961: 40)^{17}$. Por la misma razón, se ha llegado a sostener que al interpretar el pasado no sólo se buscan, o no se buscan tanto, respuestas a preguntas sobre ese pasado sino sobre el propio presente: "Aunque sea una perogrullada, es necesario recordar que una lectura del pasado, por más controlada que esté por el análisis de los documentos, siempre está guiada por una lectura del presente. Una y otra se organizan, en efecto, en función de problemáticas impuestas por una situación" (Certeau, 1978: 37).

En nuestros términos, entonces, la historia se puede entender como un esfuerzo orientado, desde las categorías del presente, hacia la comprensión de cómo y por qué sucedieron tales hechos o se dieron determinados fenómenos en el pasado. La historia, por lo tanto, para garantizar que su contenido no es mera invención se pliega al principio de la veracidad, heredado de la Antigüedad ${ }^{18}$. Esta característica fundamental permite anotar que, pese a los factores que aproximan la historia como relato al relato de ficción, la voluntad de veracidad constituye un elemento decisivo para distinguir entre un discurso de ficción y otro de carácter histórico.

\section{Notas}

1 Este artículo tiene origen en la investigación Las novelas históricas de Germán Espinosa, defendida como tesis doctoral en la Universidad Autónoma de Barcelona para optar al título de doctor en Teoría de la Literatura y Literatura Comparada.

2 El historiador Jacques Le Goff también se detiene a esclarecer la ambigüedad del término: “en las lenguas romances (y en las otras) «historia» expresa dos, cuando no tres, conceptos diferentes. Significa: 1) la indagación sobre «las acciones realizadas por los hombres» (Herodoto) que se ha esforzado por constituirse en ciencia, la ciencia histórica; 2) el objeto de la indagación, lo que han realizado los hombres. Como dice Paul Veyne, «la historia es ora la sucesión de acontecimientos, ora el relato de esa sucesión de acontecimientos»" (1977: 21).

3 Paul Ricoeur, por ejemplo, en sus estudios sobre el tiempo ha destacado la narración como un dispositivo de naturaleza antropológica a través del cual los seres humanos ordenamos y relacionamos secuencialmente los hechos para dotarlos de sentido. Este sería un rasgo de la narración que explicaría su presencia en diversidad de culturas y de producciones culturales. Remito a Tiempo y narración I e Historia y narratividad. 
${ }^{4}$ Le Goff precisa que la confusión formada alrededor de los distintos usos del término «historia» ha recibido diversas soluciones en varias lenguas: "El inglés elude esta última confusión en tanto distingue history de story, «historia» de «relato». Las demás lenguas europeas se esfuerzan más o menos por evitar esta ambigüedad” (1977: 22). Igualmente, Jorge Lozano comenta cómo en algunas lenguas se mantiene la ambigüedad y cómo se resuelve en otras: "En español historia o en italiano storia significan tanto historia como relato o narración. En inglés, en cambio, se marca la diferencia al existir dos palabras: history y story. La lengua alemana, a su vez, dispone de Geschichte e Historie. En fin, cabe mencionar el intento en Francia por distinguir, tipográficamente, Histoire (con H mayúscula) de histoire (con h minúscula)" (Lozano, 1987: 115).

${ }^{5}$ Jacques Le Goff propone una explicación etimológica de ese carácter testimonial de la historia: "La palabra «historia» (en todas las lenguas romances y en inglés) deriva del griego antiguo $1 \sigma \tau$ o (Keuck, 1934). Esta forma deriva de la raíz indoeuropea wid-, weid- «ver». De donde el sánscrito vettas «testigo», y el griego $1 \sigma \tau \omega \rho$ «testigo» en el sentido de «el que ve». Esta concepción de la vista como fuente esencial de conocimiento lleva a la idea de que $\iota \sigma \tau \omega \rho$ «el que ve» es también el que sabe: $1 \sigma \tau$ o $\rho \varepsilon \downarrow$, en griego antiguo, significa «tratar de saber», «informarse». Así que I $\sigma \tau \rho \rho \imath \eta$ significa «indagación». Tal es el sentido con que Herodoto emplea el término al comienzo de sus Historias, que son «indagaciones», «averiguaciones»" (Le Goff, 1977: 21).

6 Según Jorge Lozano: “Saber históricamente, pues, es ver. La historia, desde la historiografía griega, comienza a ser considerada como el relato de aquel que puede decir «he visto»o, en su defecto, «he oído» de personas fiables — porque han visto". Además, Lozano anota que en la Antigüedad el relato oral era considerado como fuente alternativa ante la carencia del historiador de experiencia directa de los acontecimientos. Sin embargo, la oralidad era objeto de menor confianza por implicar la mediación de un tercero y por estar sujeta a la falibilidad de la memoria. Lozano añade al respecto: "Se puede suponer que este segundo tipo de relato sería menos creíble al poseer menos fuerza el sujeto de enunciación que transmite algo que él directamente no percibió y ha de basarse en una falible e inventiva memoria" (Lozano, 1987: 24 y 19).

7 Los autores que vengo siguiendo coinciden en calificar a la Edad Media como un periodo en el que baja la calidad de la historiografía. Carlos Rama, por ejemplo, apunta que "técnicamente la historiografía cristiana corresponde a una época de decadencia de los estudios históricos” (Rama, 1981: 20). Por su parte, Jorge Lozano resalta que con "todas las características señaladas, parece confirmarse la idea de ausencia de historiadores en el sentido que se irá perfilando en sucesivos siglos. Por eso, a medida que avanza la historiografía, la Edad Media queda excluida como época de historiadores, aunque anunciaran técnicas que se encontrarán en los anticuarios" (Lozano, 1987: 33).

$8 \quad$ En palabras de Jorge Lozano: "Una vez adquirida la idea de no coincidencia entre conocimiento y percepción, idea derivada de la revolución científica de los siglos XVI y XVII, comienza a ser concebible la idea de un conocimiento mediato y, por lo tanto, el problema de la justificación de una historia del pasado se plantea necesariamente en términos diferentes. (...) Se trata de buscar una vía hacia los acontecimientos del pasado a partir de las trazas, huellas e indicios que dichos acontecimientos han dejado y que subsisten en el presente bajo formas de documentos y de monumentos" (Lozano, 1987: 40).

9 Carlos Rama también destaca ese periodo de cambios como decisivo en la configuración del concepto de historia moderna: "Definitivamente agotadas las corrientes culturales provenientes de la Antigüedad Clásica y del Cristianismo del Imperio Romano, los Tiempos Modernos definirán para la historiografía en los siglos XIV al XVIII, inclusive, una nueva perspectiva (...). En el Humanismo y el Renacimiento, será de nuevo la historia política y junto a los intereses de la clase burguesa los que definirán a los nuevos historiadores modernos, primero italianos como Maquiavelo y Guicciardini, y más tarde ya unida a la crisis de la religiosidad occidental, en el resto de Europa. El surgimiento de la erudición histórica y la aparición de la filosofía de la Historia (incluso antes de Voltaire) coinciden ya con la etapa de las Revoluciones Burguesas, que cierra la Revolución Francesa y sus secuelas en la península ibérica y en sus colonias americanas" (Rama, 1981: 28).

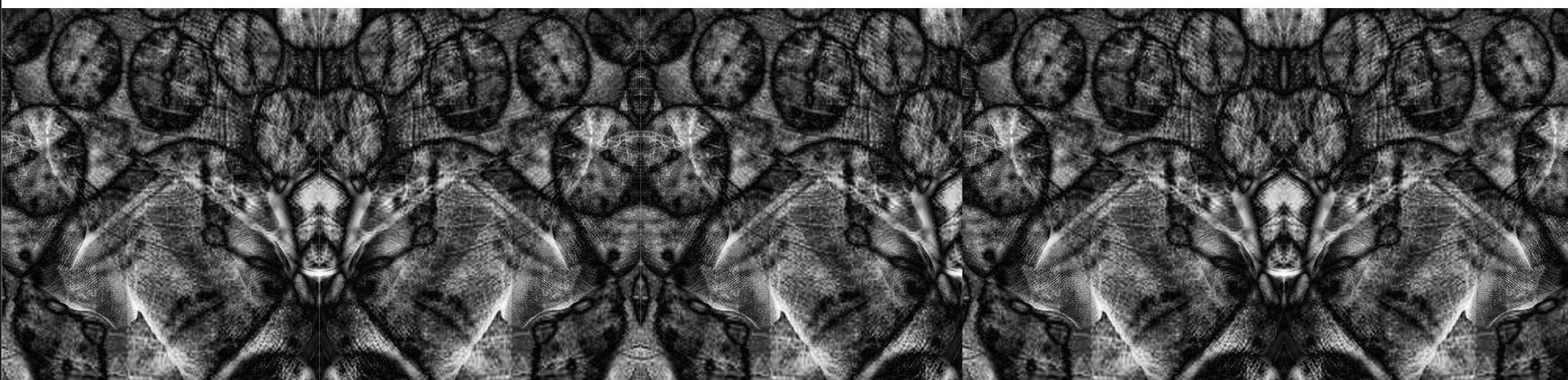


10 Celia Fernández Prieto, siguiendo a Paul Ricoeur y a Jorge Lozano, formula una observación importante al recordar que en la Poética Aristóteles se sirve de la historia como contraejemplo — sin agregar más sobre ella - para definir su concepción de la mímesis poética. En efecto, es cierto que Aristóteles sólo menciona la historia en este pasaje para distinguir teóricamente la poesía — el poema trágico - de un tipo de escritura - la historiográfica- que se ocupa de lo particular y de decir lo que sucedió. Sin embargo $-\mathrm{y}$ este es el factor que subrayan investigadores como Jorge Lozano o García Gual-, si bien algunos autores clásicos de la historia se esmeraban por desterrar todo elemento ficticio de sus escritos, en aquel tiempo la distinción entre lo histórico y lo inventado no tenía la claridad que a partir del juicio de Aristóteles se podría pensar que existía (Cfr. Fernández, 1998: 42).

11 Según Peter Burke, los principios que animaban la historia practicada por Ranke se podrían sintetizar así: "Una vista desde arriba, en el sentido de que siempre se ha centrado en las grandes hazañas de los grandes hombres, (...) su insistencia en la necesidad de basar la historia escrita en documentos oficiales procedentes de los gobiernos y conservados en archivos (...), la historia es objetiva. La tarea del historiador es ofrecer al lector los hechos o, como decía Ranke en una frase muy citada, contar «cómo ocurrió realmente»" (Burke, 1991: 13-18).

12 En este texto, Nietzsche caracterizó tres tipologías de historia: la monumental, con la cual comprendió la historia de los grandes hombres y sucesos, la llamada historia universal que uniría a la humanidad, a la que llegó a calificar como "ficción mística"; la historia anticuaria, con la cual asoció el espíritu que preserva y venera el pasado, un espíritu para el que todo lo pasado es importante y por ello no sabe distinguir entre lo que realmente posee algún valor y lo que no lo posee; y con el modo de una historia crítica relacionó el juicio sobre el pasado, modo que valoró como peligroso por cuanto se inclinaría por borrar del pasado aquello que no fuera del agrado en el presente (Cfr. Nietzsche, 1874). Por si fuera poco — en lo que a mi modo de ver constituye quizás el principal antecedente de la crítica contemporánea a la historia y a la cultura occidental_-, el mismo Nietzsche, quien pensó que no hay hechos en sí, sino interpretaciones, arremetió contra la tradición demoliendo con su filosofía del martillo figuras e instituciones históricas como Sócrates, el cristianismo, la verdad, lo bueno y lo malo.

13 La crítica al positivismo fue formulada también a finales de la década de 1920 por la llamada escuela de los Annales:

“Todo parte del examen crítico de los conceptos fundamentales de la historia «positivista», o «historizante», que muy pronto se llamará del «acontecer», tal y como la ilustraba, por ejemplo, C. Seignobos a la vuelta del siglo: una historia que propone como una exigencia crítica la de la erudición (la fijación del documento y, esto supuesto, el control del hecho que refiere) y considera que el hecho histórico es un dato cuyo desglose y significación vienen dados objetivamente; con lo cual el cometido del historiador se reduce a ordenar los hechos según una narración igualmente objetiva, la cronología que él se contenta con hacer visible"(Le Goff, Chartier, 1988: 19).

14 Paul Ricoeur es claro al mantener el concepto de objetividad en historia, pero ahora diferenciado del contenido que Ranke había puesto en el término: "La objetividad debe tomarse aquí en su sentido epistemológico más estricto: es objetivo lo que el pensamiento metódico ha elaborado, ordenado, comprendido y lo que de este modo puede hacer comprender. Esto es verdad de las ciencias físicas y biológicas; y también es verdad de la historia. Por consiguiente, esperamos de la historia que conduzca al pasado de las sociedades humanas a esa dignidad de la objetividad” (Ricoeur, 1955: 23). Pero el mismo Ricoeur reivindica la incidencia de la subjetividad en la indagación histórica: "Tiene razón mil veces (Marc Bloch) al negar que la tarea del historiador sea la de restituir las cosas «tal como sucedieron». La historia no pretende hacer revivir, sino re-componer, re-construir, o sea, componer y construir un encadenamiento retrospectivo. La objetividad en historia consiste precisamente en esta renuncia a coincidir, a revivir (...). La historia a través del historiador no retiene, no analiza y no relaciona más que los sucesos importantes. Aquí es donde interviene la subjetividad del historiador en un sentido original respecto a la del físico, bajo la forma de esquemas interpretativos" (25 y 28). 
